\title{
Threshold Value of Anti-Mullerian Hormone for the Diagnosis of Polycystic Ovary Syndrome in Hung Vuong Hospital, Vietnam
}

ISSN: 2640-9666

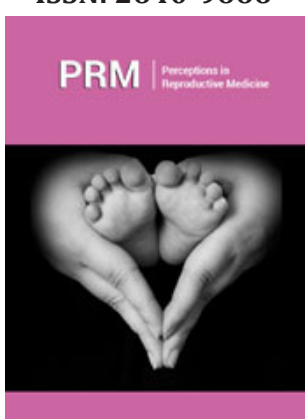

*Corresponding author: Tuyet Hoang TD, Director of Hung vuong Hospital, Hung Vuong hospital, Vietnam

Submission: 眥 March 20, 2020

Published: 鴊April 14, 2020

Volume 3 - Issue 5

How to cite this article: Tuyet Hoang TD, Huynh Nguyen KT, Huong DT. Threshold Value of Anti-Mullerian Hormone for the Diagnosis of Polycystic Ovary Syndrome in Hung Vuong Hospital, Vietnam. Perception in Reproductive Medicine.3(5). PRM.000574.2020.

DOI: $10.31031 /$ PRM.2020.03.000574

Copyright@ Tuyet Hoang TD, This article is distributed under the terms of the Creative Commons Attribution 4.0 International License, which permits unrestricted use and redistribution provided that the original author and source are credited.

\author{
Tuyet Hoang $\mathrm{TD}^{1 *}$, Huynh Nguyen $\mathrm{KT}^{2}$ and Huong $\mathrm{DT}^{3}$ \\ ${ }^{1}$ Director of Hung vuong Hospital, Hung Vuong hospital, Vietnam \\ ${ }^{2}$ Pham Ngoc Thach University of Medicine, Vietnam \\ ${ }^{3}$ Hung Vuong hospital, Vietnam
}

\begin{abstract}
Abstract: Polycystic ovary syndrome (PCOs) is one of the most common endocrine disorders in women, accounting for $8-13 \%$ of women in reproductive age. Anti-Mullerian hormone (AMH) is secreted only by the granular cells of the ovaries, starting from 25 weeks of pregnancy to menopause. AMH is involved in follicle development and the sensitivity of follicles to FSH. Serum AMH increased in the group with PCOs, but the threshold for diagnosis and prognosis is a matter of great concern.
\end{abstract}

Objectives: Identify serum AMH cutoff threshold in predicting a PCOs at Hung Vuong hospital and related factors.

Methods: A cross-sectional study of 275 infertility patients with 60 cases of had PCOs and 215 without PCOs in Hung Vuong Hospital's Department of Infertility, which met the sample selection criteria from March 15, 2018 to August 20, 2019.

Results: (1) AMH with cutoff of $6.5 \mathrm{ng} / \mathrm{ml}$, sensitivity of $70 \%$, specificity of $77.4 \%$ can be used to predict PCOs. (2) There is no relationship between AMH and BMI in both groups of PCOs and without PCOs. Some characteristics of PCOs: The average age of women with PCOs is $28.03 \pm 2.74$ lower than the group without PCOs ( $\mathrm{p}=0.02)$. Menstrual disorders and images of polycystic ovaries are the two most common symptoms in PCOs. Androgen intensity only accounts for a few. Most women with PCOs have BMI within normal limits (60\%). The rate of LH in the PCOs group was higher than that of the group without PCOs ( $p$ <.001). Conclusion: serum AMH is valuable for diagnosis in PCOS. However more research is needed in the future.

Keywords: PCOs, cross - sectional study, cut threshold, Anti - Mullerian hormone Polycystic ovary syndrome (PCOs) is one of the most common endocrine disorders in women, accounting for $8-13 \%$ of women of reproductive age [1], PCOs can be diagnosed clinically, biochemically and by ultrasound. Following the consensus of the conference in Rotterdam, PCOs were diagnosed when there were two of three criteria: cyclic ovarian disorders, clinical and biochemical androgen increase, polycystic ovarian image on ultrasound [2].

\section{Introduction}

Recently, Anti-Mullerian hormone (AMH) has been known as a survey for ovarian reserve. AMH is secreted by the granulocytes of prokaryotic and follicular cysts, which play an important role in early follicular development. Serum AMH also plays an important role in preventing oocyte selection to be the dominant follicle [3]. Many studies have shown the role of serum AMH in diagnosing PCOs [4]. However, due to the diversity in AMH testing, it is difficult to define a serum AMH threshold to diagnose PCOs for all places. Age may affect the relationship of AMH and hormones, with some authors recommending avoiding the diagnosis of PCOs before age 18 [5].

PCOs are characterized by an increase in the number of oocytes at all stages of follicle development [6], in particular an increase in many cavity follicles and small-sized follicles [7]. Therefore, serum AMH-reflecting the source of pre-cysts and small cysts, increases 2-4 times higher in PCOs compared to normal women [8]. Increased serum AMH is thought to be due to an increase in the number of pre-cavity cysts and small-sized cysts. However, AMH secreted by granulocytes increased by 75 times in women with no ovum PCOs and 20 times in women with normal ovulatory PCOs compared to women with normal ovarian activity. The intrinsic regulatory disturbance of granulocytes, increased overexpression of AMH type 2 receptors (AMHRII) also increases serum AMH in PCOs [9]. 
The cause of serum AMH increase in polycystic ovaries is unknown but there is evidence supporting the role of androgens. There is a positive correlation between androgen and serum AMH, and excessive androgen production may be due to shell cell defects in PCOs [10]. Many studies have been done to evaluate the accuracy of serum AMH in the diagnosis of PCOs and determine the appropriate diagnostic threshold. There is no consensus on the serum AMH threshold used to diagnose PCOs. This serum AMH value ranges from $2.8 \mathrm{ng} / \mathrm{ml}$ to $8.4 \mathrm{ng} / \mathrm{ml}$ [11]. A meta-analysis gave a diagnostic threshold of PCOs of $4.7 \mathrm{ng} / \mathrm{ml}$ with a sensitivity of $79.4 \%$ and a specificity of $82.8 \%$ and AUC of 0.87 [12]. In Vietnam, research on polycystic ovary syndrome and serum AMH has not been done much, especially research on serum AMH cutoff threshold for diagnosing polycystic ovary syndrome. From the above fact, we have conducted a research with the purpose of finding an appropriate serum $\mathrm{AMH}$ cut threshold to diagnose PCOs according to Rotterdam standards at Hung Vuong Hospital, Vietnam.

Our research has the following goals:

A. Determination of serum AMH cut threshold in predicting the PCOs at Hung Vuong Hospital.

B. Determine the correlation between serum AMH and BMI.

\section{Objects and Methods}

Research design: Cross-sectional research

Subjects: Female infertility patients at the Department of Infertility of Hung Vuong Hospital met the sample selection criteria from March 15th, 2018 to August 20th, 2019.

Criteria for admission: The presence of 2 ovaries and the image of the ovaries observed on ultrasound.

Exclusion criteria: Patients diagnosed with congenital adrenal hyperplasia, androgenic tumors, Cushing's syndrome, hyperactactinemia, thyroid dysfunction and other endocrine disorders, autoimmune disease, amenorrhea hypothalamus, premature ovarian failure. Age $<18$ or $>35$. Use oral contraception pill. Ovarian tumors, ovarian cysts, endometriosis.

The sample size is calculated by formula (13):

$$
\begin{aligned}
F P+T N & =\frac{\mathrm{z}_{\mathrm{a}}^{2} \times \mathrm{p}_{\mathrm{sp}} \times\left(1-\mathrm{p}_{\mathrm{sp}}\right)}{\mathrm{w}^{2}} \\
\mathrm{n}_{\mathrm{sp}} & =\frac{\mathrm{FP}+\mathrm{TN}}{1-\mathrm{p}}
\end{aligned}
$$

In which: FP: false positive; TN: it's negative; p_sp: specificity of the test: 0,8 (12); Z_ $\alpha: 1.96$; W: error of probability of false positive and true negative: 0.05 ; p: prevalence of the disease: 0.1 (1). The result is $\mathrm{N}=275$. Sampling method: Based on the list of infertility patients stored at Hung Vuong Hospital's Department of Infertility, we collected samples that met the sampling criteria. Samples are selected according to the convenient selection method until a sufficient number of sample sizes are available. After that, we proceeded to collect the data according to the collected form. The study selected the gold standard based on the diagnostic criteria of PCOs as agreed by the Rotterdam Conference 2003. Endocrine tests: $\mathrm{LH}, \mathrm{FSH}$, estradiol, testosterone, $\mathrm{AMH}$ tests are performed on day 2-3 of the cycle. periods. The AMH test is an ELISA test: Gen II. We use IBM SPSS software 20 for data entry and data analysis.

\section{Result}

Select cut -off serum AMH threshold by drawing ROC curve and a detailed breakdown of cut points, then select the optimal cut point by calculating the maximum value of Youden index ( $\mathrm{J}=\mathrm{Se}+$ Sp -1) and maximum value minor of $d=\sqrt{\left.(1-S n)^{2}+(1-S p)^{2}\right)}$ (Figure 1). The area under the curve is 0.758 with $95 \%$ CI [0.70-0.82], the suitable serum AMH cut - off point is 6.5 with $70 \%$ sensitivity, $77.4 \%$ specificity (Table $1 \& 2$ ).

Table 1: Group epidemiological characteristics with PCOs and without PCOs $(n=275)$.

\begin{tabular}{|c|c|c|c|}
\hline Factor & PCOs (n=60) & Without PCOs (n=215) & P Value \\
\hline Age (year) & $28.03 \pm 2.74$ & $8(3.7 \%)$ \\
\hline $18-24$ & $9(15 \%)$ & $128(59.5 \%)$ \\
\hline $25-30$ & $37(61.7 \%)$ & $79(36.7 \%)$ & 0.02 \\
\hline $31-35$ & $14(23.3 \%)$ & $163(75.8 \%)$ \\
\hline Infertility & & $52(24.2 \%)$ \\
\hline Primary & $43(71.7 \%)$ & $21.37(19.83-22.83)$ \\
\hline Secondary & $17(28.3 \%)$ & $4(3-7)$ & $0.51(\mathrm{a})$ \\
\hline BMI $\left(\mathrm{kg} / \mathrm{m}^{2}\right)$ & $22.38(20.77-23.53)$ & $6(5-7)$ & 0.02 \\
\hline AMH $(\mathrm{ng} / \mathrm{ml})$ & $8.33 \pm 3.77$ & $5(4-7)$ & $<0.001(\mathrm{~b})$ \\
\hline FSH $(\mathrm{IU} / \mathrm{ml})$ & $6.05 \pm 1.58$ & $30.5(23-42)$ & $0.18(\mathrm{~b})$ \\
\hline LH $(\mathrm{IU} / \mathrm{ml})$ & $10.17 \pm 5.77$ & $17(13-22)$ & $<0.001(\mathrm{~b})$ \\
\hline Estradiol $(\mathrm{pg} / \mathrm{ml})$ & $34.5(25-44)$ & $11(8-15)$ & $0.05(\mathrm{~b})$ \\
\hline Prolactin $(\mathrm{ng} / \mathrm{ml})$ & $14(10-23)$ & $0.17(\mathrm{~b})$ \\
\hline AFC & $26.58 \pm 3.15$ & $<0.001(\mathrm{~b})$ \\
\hline
\end{tabular}

a): Chi-square test; (b): Mann Whitney test AFC: Antral Follicle Count. 
Table 2: $\mathrm{AMH}$ relationship $\geq 6.5 \mathrm{ng} / \mathrm{ml}$ and PCOs.

\begin{tabular}{|c|c|c|c|c|}
\hline $\begin{array}{c}\text { AMH } \\
(\mathbf{n g} / \mathbf{m l})\end{array}$ & PCOs & Without PCOs & P Value & KTC 95\% \\
\hline$\geq 6.5$ & 40 & 57 & $<0.001$ & 5.54 \\
\hline$<6.5$ & 20 & 158 & & \\
\hline
\end{tabular}

Serum $A M H \geq 6.5 \mathrm{ng} / \mathrm{ml}$ can be used to diagnose PCOs with $\mathrm{OR}=5.54,95 \% \mathrm{Cl}$ [2.99-10.27], $\mathrm{p}<0.001$.

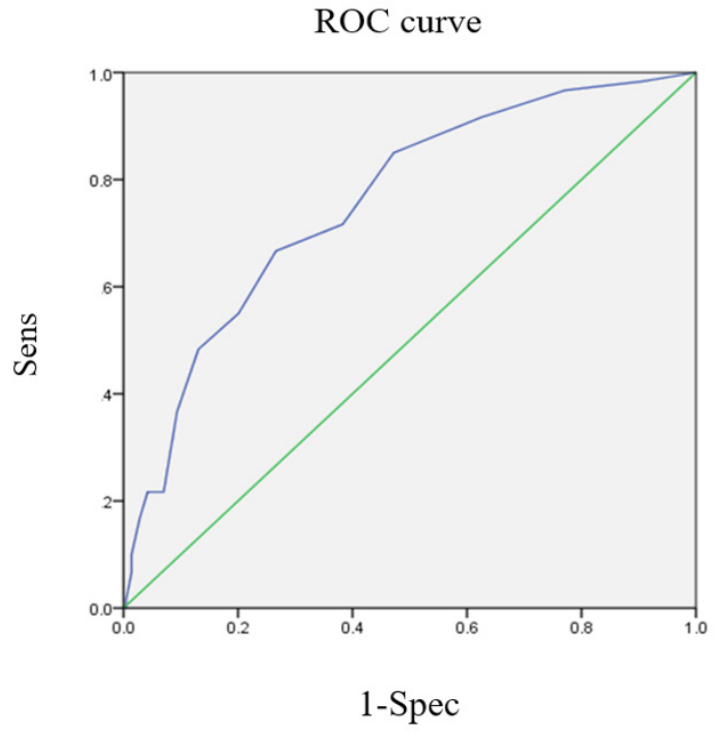

Figure 1: ROC curve of serum AMH in the diagnosis of NCD.

\section{Discussion}

In the world, many studies have been conducted from 20062018 to determine the role of AMH in diagnosing PCOs. These studies all used the consensus of the 2003 Rotterdam Conference to diagnose PCOs. There are 3 studies done in the white race, 3 studies done in Asia. The two studies that used the AMH assay were Gen II varieties in our study, which were from Taiwan and Indonesia. The majority of research designs are controls. Three studies sampled from infertility, three from a general population. In our study, the AMH value in PCOs group was significantly higher $(p<0.001)$ compared to the group without PCOs. AMH is highly sensitive and specific in diagnosing PCOs, the area under the curve is 0.758 with 95\% confidence interval [0.7-0.82]. With AMH cutoff point of $6.5 \mathrm{ng} /$ $\mathrm{ml}, \mathrm{AMH}$ can diagnose PCOs with a sensitivity of $70 \%$, a specificity of $77.4 \%$ (OR=5.54, 95\% CI [2.993-10.267]). The AMH cut-off threshold for diagnosing PCOs in Taiwan is $7.3 \mathrm{ng} / \mathrm{ml}$ with $70 \%$ sensitivity, $76 \%$ specificity is quite similar to the study with our study of $6.5 \mathrm{ng} / \mathrm{ml}, 70 \%, 77.4 \%$ in order. However, this study uses a sample from the general population, so the results are different from our study. Wiweko's 2011 study [13,14], in Indonesia, has the same characteristics as ours: sampling population, research design, AMH testing and Asian racial similarity, Their AMH cutoff is $4.45 \mathrm{ng} /$ $\mathrm{ml}$ with $76 \%$ sensitivity, $74.6 \%$ specificity. However, the sample size of Wiweko was not very large (142 people). Tremellen's study in
2015 [15], with a very large sample size, using modern AMH assays (automatic elecsys) for AMH cutoff of $7.6 \mathrm{ng} / \mathrm{ml}$ with a sensitivity of $76 \%$ in order, $87 \%$.

Some characteristics of PCOs: The average age of women PCOs is $28.03 \pm 2.74$ (yrs) lower than the group without PCOs $(\mathrm{p}=0.02)$. Menstrual disorders and polycystic ovarian images are the two most common symptoms in PCOs. Androgen intensity only accounts for a few. Most women with PCOs have BMI within the normal limits (60\%). Serum LH was higher in PCOs than nonPCOs ( $\mathrm{p}<0.001)$. Regarding age, in our study, the average age of women PCOs was $28.03 \pm 2.74$. This feature is quite similar to the research in the world. The study of Casadei et al. [16] in Italy, the average age of women PCOs is $30.6 \pm 3$. The study of the authors' group in Indonesia [14], the average age of women PCOs is 29.55 \pm 3.94 . We noted that the average age of PCOs was lower than that of women without PCOs, this difference was statistically significant with $\mathrm{p}=0.02$. The studies of Johnstone [17] and Wiweko [14] also recorded similar. This may be explained by a gradual decrease in the number of cavity-filled ovules and women with symptomatic PCOs who visit earlier, are diagnosed and treated earlier.

In terms of infertility classification, most of our study subjects were primary infertility, accounting for over $70 \%$ in both groups with and without PCOs and no difference between the two groups. 
This is consistent with the pathogenetic characteristics of PCOs the cause of infertility due to frequent ovulation. Regarding obesity, the median BMI of PCOs in our study was $22.38 \mathrm{~kg} / \mathrm{m}^{2}$ higher than the non-PCOs group at $21.37 \mathrm{~kg} / \mathrm{m}^{2}$. The difference was statistically significant ( $p=0.023$ ) between the two groups of PCOs and without PCOs. Basically, the serum FSH in PCOs group was not different from the without PCOs group. According to Pellat et al., Serum FSH does not affect $\mathrm{AMH}$ secretion and AMH gene expression in granulocytes, but in PCOs, AMH decreases by up to $30 \%$ after FSH injection [11]. Serum LH in the PCOs group was $10.17 \pm 5.77 \mathrm{IU} / \mathrm{ml}$, significantly higher than the without PCOs group ( $\mathrm{p}<0.001$ ). Wiweko's study [14] also has similar results with ours. According to Wiweko [14], in the group with PCOs, serum LH had an average value of $10.41 \pm$ $8.12 \mathrm{IU} / \mathrm{ml}$, significantly higher than the group without PCOs. Many studies confirm a relationship between serum AMH and serum $\mathrm{LH}$ because they find that in patients with PCOs, serum LH is elevated in subjects with high AMH [18].

Regarding ultrasound AFC (Antral follicle count), the average AFC of the group with PCOs was $26.58 \pm 3.15$, significantly higher ( $p<0.001$ ) than the group without the PCOs (median AFC was 11). This is also noted in other studies around the world: Casadei [16] and Song [19]. Regarding serum AMH, in the PCOs group, the mean value of serum AMH was $8.33 \pm 3.77 \mathrm{ng} / \mathrm{ml}$, which is double that of the without PCOs group of $4 \mathrm{ng} / \mathrm{ml}$. This difference is statistically significant $\mathrm{p}<0.001$. This result is similar to that of Wiweko [14], the average serum AMH in the PCOs group was $9.5 \pm 5.11 \mathrm{ng} / \mathrm{ml}$ in the group without PCOs was $3.53 \pm 1.95$, with the Statistical differences were significant at $\mathrm{p}<0.001$. According to Casadei [16], serum AMH in the group with PCOs is $8.4 \pm 4.8 \mathrm{ng} / \mathrm{ml}$, in the group without PCOs $2.8 \pm 2.2 \mathrm{ng} / \mathrm{ml}$. Dewailly et al. [20] suggested that serum AMH is an indicator of follicular growth better than AFC. Therefore, serum AMH testing may be an alternative diagnostic standard in PCOs in clinical practice. Regarding prolactin, the group with PCOs was 14 (10-23) pg/ml, the group without PCOs was 17 (13-22) $\mathrm{pg} / \mathrm{ml}$. There was no statistically significant difference between the two groups ( $\mathrm{p}=0.17)$. Research results of Wiweko [14], prolactin value in PCOs group is $9.85 \mathrm{ng} / \mathrm{ml}$, lower than our study. Regarding serum estradiol, the group with PCOs was 34.5 (28.2544) pg/ml. Wiweko's study [14] also recorded the results as we did 38.0 (5.42-191.0)ng/ml. A study of Casadei [16] recorded a higher result of $44.0 \pm 17.2 \mathrm{ng} / \mathrm{ml}$. Thus, in women with PCOs there was an increase in serum estradiol levels. This is probably due to a decrease in SHGB (Sex Hormone Binding Globulin) concentration, which increases the concentration of estradiol that is not associated with SHGB and increases the bioactive estradiol concentration.

\section{Conclusion}

Through the study of 275 infertility patients, including 60 cases of PCOs and 215 cases of no PCOs, draw some conclusions as follows: serum AMH with cutoff of $6.5 \mathrm{ng} / \mathrm{ml}$, sensitivity $70 \%$, specificity $77.4 \%$ can be used to predict PCOs. There was no relationship between serum AMH and BMI in both PCOs and without PCOs.

\section{References}

1. Azziz R, Carmina E, Chen Z, Dunaif A, Laven JS (2016) Polycystic ovary syndrome. Nat Rev Dis Primers 2: 16057.

2. Rotterdam E (2004) Revised 2003 consensus on diagnostic criteria and long-term health risks related to polycystic ovary syndrome. Fertil Steril 81(1): 19-25.

3. Yue CY, Lu LK, Li M, Zhang QL, Ying CM (2018) Threshold value of antiMullerian hormone for the diagnosis of polycystic ovary syndrome in Chinese women. PLoS One 13(8): e0203129.

4. Singh AK, Singh R (2015) Can anti-Mullerian hormone replace ultrasonographic evaluation in polycystic ovary syndrome? A review of current progress. Indian J Endocrinol Metab 19(6): 731-743.

5. Shayya R, Chang RJ (2010) Reproductive endocrinology of adolescent polycystic ovary syndrome. BJOG 117(2): 150-155.

6. Maciel GA, Baracat EC, Benda JA, Markham SM, Hensinger K (2004) Stockpiling of transitional and classic primary follicles in ovaries of women with polycystic ovary syndrome. J Clin Endocrinol Metab 89(11): 5321-5327.

7. Bhide P, Dilgil M, Gudi A, Shah A, Akwaa C (2015) Each small antral follicle in ovaries of women with polycystic ovary syndrome produces more antimullerian hormone than its counterpart in a normal ovary: an observational cross-sectional study. Fertil Steril 103(2): 537-541.

8. Azziz R, Carmina E, Dewailly D, Diamanti-Kandarakis E, EscobarMorreale HF, et al. (2009) The Androgen Excess and PCOS Society criteria for the polycystic ovary syndrome: the complete task force report. Fertil Steril 91(2): 456-488.

9. Alebic MS, Stojanovic N, Duhamel A, Dewailly D (2015) The phenotypic diversity in per-follicle anti-Mullerian hormone production in polycystic ovary syndrome. Hum Reprod 30(8): 1927-1933.

10. Carlsen SM, Vanky E, Fleming R (2009) Anti-Mullerian hormone concentrations in androgen-suppressed women with polycystic ovary syndrome. Hum Reprod 24(7): 1732-1738.

11. Piouka A, Farmakiotis D, Katsikis I, Macut D, Gerou S (2009) AntiMullerian hormone levels reflect severity of PCOS but are negatively influenced by obesity: relationship with increased luteinizing hormone levels. Am J Physiol Endocrinol Metab 296(2): 238-243.

12. Iliodromiti S, Kelsey TW, Anderson RA, Nelson SM (2013) Can antiMullerian hormone predict the diagnosis of polycystic ovary syndrome? A systematic review and meta-analysis of extracted data. J Clin Endocrinol Metab 98(8): 3332-3340.

13. Stephen BH, Steven RC, Warren SB (2007) Designing clinical research. In: $3^{\text {rd }}$ (edn)

14. Wiweko B, Maidarti M, Priangga MD, Shafira N, Fernando D, et al. (2014) Anti-mullerian hormone as a diagnostic and prognostic tool for PCOS patients. J Assist Reprod Genet 31(10): 1311-1316.

15. Tremellen K, Zander-Fox D (2015) Serum anti-Mullerian hormone assessment of ovarian reserve and polycystic ovary syndrome status over the reproductive lifespan. Aust N Z J Obstet Gynaecol 55(4): 384389.

16. Casadei L, Fanisio F, Sorge RP, Collamarini M, Piccolo E, et al. (2018) The diagnosis of PCOS in young infertile women according to different diagnostic criteria: the role of serum anti-Mullerian hormone. Arch Gynecol Obstet 298(1): 207-215.

17. Johnstone EB, Rosen MP, Neril R, Trevithick D, Sternfeld B, et al. (2010) The polycystic ovary post-rotterdam: a common, age-dependent finding in ovulatory women without metabolic significance. J Clin Endocrinol Metab 95(11): 4965-4972. 
18. La Marca A, Volpe A (2006) Anti-Mullerian hormone (AMH) in female reproduction: is measurement of circulating $\mathrm{AMH}$ a useful tool? Clin Endocrinol (Oxf) 64(6): 603-610.

19. Song DK, Oh JY, Lee H, Sung YA (2017) Differentiation between polycystic ovary syndrome and polycystic ovarian morphology by means of an antiMullerian hormone cutoff value. Korean J Intern Med 32(4): 690-698.
20. Dewailly D, Andersen CY, Balen A, Broekmans F, Dilaver N, et al. (2014) The physiology and clinical utility of anti-Mullerian hormone in women. Hum Reprod Update 20(3): 370-385.

For possible submissions Click below: 